Journal of Research in Nursing

Vol. 3, No. 1, 2017

Print ISSN 2244-2723

University of Cebu

Cebu City, Cebu, Philippines

\title{
Assessment of Students' Performance in Psychiatric Nursing
}

\author{
Vivian Aimee M. Diamante \\ Mauro Allan P. Amparado
}

\section{Abstract}

This study assessed the students' performance in Psychiatric Nursing. It further described the profile in terms of assessment test, Nursing Care Management 105 (NCM 105) final grade, performance of nursing students in Psychiatric Nursing, and the relationship between the respondents' profile and performance. The findings of the study served as basis for a proposed action plan.

The descriptive-correlational design was used and an adapted questionnaire as instrument for data collection. The respondents were all the 46 level 4 nursing students who previously took and passed the NCM 105 in the second semester of SY 2011-2012 at the University of Cebu Lapu-Lapu and Mandaue, Mandaue City, Cebu, Philippines. Treatment of data include simple percentage and chi-square Test of Independence.

The findings showed a majority of the respondents failed in the assessment test of Psychiatric Nursing administered by the review provider despite recently passing the NCM 105 course based on the final grade. On the other hand, their ratings were fair during the Psychiatric Nursing performance assessment. 
Furthermore, there was a significant relationship between the respondents' profile and performance.

In conclusion, seniors in the College of Nursing will improve their academic achievement in Psychiatric Nursing if they are motivated or reinforced with the aid of good models of learned behavior. Consequently, future studies must be conducted on students' approach to learning and factors that will motivate a student to perform.

Recommended citation: Diamante, V. A. M. \& Amparado, M. A. P. (2017). Assessment of Students' Performance in Psychiatric Nursing. Journal of Research in Nursing, 3(1), 60-69. 